\title{
O TRÁFICO INTERNACIONAL DE SERES HUMANOS, ASPECTOS CRIMINOLÓGICOS DO LENOCÍNIO E SUA ABORDAGEM NA LEGISLAÇÃO BRASILEIRA.
}

\author{
Hugo Stéphano Rufino Belezzi \\ Universidade do Oeste Paulista - UNOESTE, Curso de Direito, Presidente Prudente, SP.
}

\begin{abstract}
RESUMO
O tráfico de pessoas tem como alvo mulheres e crianças principalmente, onde, de forma diária tem as suas prerrogativas de direitos e vidas roubadas por um descontrole do ser humano: o tráfico sexual. Pessoas estas são iludidas através de ofertas de emprego ou mesmo levadas a força para diversas regiões do globo, e na maioria das vezes, estas nunca mais retornem para os seus lares. $\mathrm{O}$ tráfico de pessoas não é coisa oriunda apenas no século XXI, delito este teve a sua origem na antiguidade, na Grécia e em Roma, e não tinha como objetivo fins lucrativos, eram apenas prisioneiros de guerra que trabalhavam em regime de escravidão, os sujeitos desse crime, bem como seus perfis criminológicos Apesar de não ser muito divulgado, esse tipo de tráfico tem rotas mundiais que trazem uma vida de luxo e lascívia aos traficantes.
\end{abstract}

Palavras-chave: Tráfico humano, lenocínio, legislação.

THE INTERNATIONAL TRAFFIC OF HUMAN BEINGS, CRIMINOLOGICAL ASPECTS OF LENOCÍNIO AND ITS APPROACH TO BRAZILIAN LEGISLATION

\begin{abstract}
Trafficking in human beings targets women and children mainly, almost daily, have their prerogatives of rights and lives stolen by a lack of control of the human being: sex trafficking. These people are deluded by offers of employment or even taken to force to different regions of the globe, and most of the time, these never return to their homes. Trafficking in human beings is not only a matter of the twenty-first century. This crime originated in antiquity, Greece and Rome, and was not for profit purposes, it was only prisoners of war who worked in slavery, the subject to this crime, as well as their criminological profiles. Although not widely publicized, this type of trafficking has world routes that bring a life of luxury and lust to the traffickers.
\end{abstract}

Keywords: Human trafficking, pimping, legislation. 


\section{INTRODUÇÃO}

Diariamente, jovens e crianças são retirados de sua infância inocente quase sempre de forma abrupta para serem inseridas num mundo sem escrúpulos, onde o medo às controla e fazem delas faz seu principal pensamento, onde que terão que satisfazer seus clientes para obterem dinheiro, não sofrer violência física de seus "donos" e poderem quitar seus débitos e libertarem-se desse infortúnio.

Serão escolhidas as crianças e mulheres sendo estas as mais bonitas. Porém, o fim delas acaba sendo forma mais trágica: serão escolhidas para sem exploradas sexualmente, para o realizarem trabalhos forçados e trabalhos escravos e, quando não servirem mais, seus órgãos serão retirados para serem vendidos de forma clandestina.

No transcorrer deste artigo, será possível a identificação da lascívia dos traficantes e clientes do tráfico de seres humanos na qual esta prática não possuem limites. É difícil pensarmos como um ser humano adulto em plena consciência pode sentir desejo por uma criança de seis anos, pois esta ainda não possui os aspectos físicos e fisiológicos do corpo de mulher.

A ganância do ser humano é de maneira tão grande que, o tráfico de pessoas ocorre em escala mundial. $O$ atual tráfico de pessoas difere-se do tráfico de séculos passados, onde o único objetivo era a escravização e trabalho forçado em lavouras para prisioneiros de guerra ou de escravos negros. $O$ tráfico de pessoas no século XXI visa, principalmente, o lenocínio.

$O$ presente artigo mostrará informações sobre as origens e rotas do tráfico, o perfil criminológico dos agentes que cometem tal delito e a legislação atinente ao assunto.

\section{ETIMOLOGIA E ORIGENS DO TRÁFICO HUMANO}

O termo Lenocínio vem do latim lenocinium, que significava o tráfico de escravas para a prostituição. (MIRABETE, p. 436)

Nucci (2017, p.715) conceitua lenocínio como a prestação de apoio, assistência e incentivo à vida voluptuosa de outra pessoa, dela tirando proveito. Os agentes do lenocínio são peculiarmente chamados de rufião (ou cafetão) e proxeneta.

O Lenocínio trata-se de uma prática criminosa que consiste em explorar, estimular ou facilitar a prostituição sob qualquer forma ou aspecto, havendo ou não mediação direta ou intuito de lucro.

O tráfico de pessoas é algo que parece não existir somente nos tempos atuais, sendo o pensamento de forma errônea na qual temos que abordar de forma sucinta sua origem e evolução.

Nesse sentido, a origem da exploração do tráfico de pessoas remonta à Antiguidade Clássica, na Grécia e em Roma, que através das vitórias nas guerras tinha como objetivo a obtenção de prisioneiros de guerra para serem utilizados como escravos, sem caráter comercial. Mas o primeiro caso de tráfico de pessoas que teve o lucro como objetivo aconteceu não muito longe dali, na Itália, entre os séculos XIV e XVII.

Até mesmo membros da nobreza, como o rei Luís XV da França tinham crianças e adolescentes sob seu domínio para poder manter relações sexuais com elas, em troca de proteção e sustento de suas famílias, estas em situação de extrema miserabilidade.

Em Londres, no século XVIII, a prostituição, principalmente a infantil era muito comum, as crianças da classe trabalhadora eram as que mais sofriam com os abusos, acabavam ficando nas ruas ou eram levadas a prostíbulos pelos próprios pais nas quais eram por vezes vendidas ou para ficarem à disposição dos donos que então as utilizavam para a prática da prostituição e satisfazerem a sua lascividade e de frequentadores desses locais.

Na América, o tráfico humano teve início desde a sua descoberta, e seu objetivo foi a colonização por países europeus. De acordo com Shecaria e Silveira a mais antiga referência histórica do tráfico de pessoas está sem qualquer dúvida no tráfico negreiro. O Brasil "colônia" 
sempre manteve a escravidão, sendo o último país da América a aboli-la. No início do século XIX a existência de mão-de-obra escrava já não interessava mais aos ingleses, que tinham grandes interesses no mercado consumidor na América do Sul.

As regiões onde possuem a menor concentração de renda e por consequência as mais pobres tendem a ter um maior número de pessoas a serem utilizadas para o tráfico. No Brasil, por exemplo, o uso do tráfico é definido por região: no Nordeste o indicador é o turismo sexual; no Norte é o lenocínio; no Centro-Oeste também é a prostituição; no Sudeste o turismo sexual, a prostituição e a pornografia; e no Sul a prostituição e o tráfico para adoção ilegal.

Podemos garantir que uma das maiores causas desse tipo de tráfico é a facilidade com que conseguem adentrar com as pessoas em outros países. A corrupção por vezes começa dentro dos órgãos policiais, que contribuem para que os traficantes ultrapassem pelos limites territoriais, estes oferecendo grandes importâncias e a liberdade de escolherem, principalmente mulheres jovens e crianças para assim então, a satisfação de seus desejos sexuais. Além disso, a facilidade da promoção do lenocínio, onde as próprias famílias entregam seus filhos para trabalharem no exterior, onde estão com a convicção que estão indo à trabalho realmente e não sendo utilizadas para serem exploradas sexualmente, ou por vezes as entregam mesmo sabendo o que acontecerá com eles, e ainda quando as estas são pegas a força.

\section{LUCRATIVIDADE E ROTAS}

Embora menos comentado e noticiado que outros crimes transnacionais graves como o tráfico internacional de drogas, o tráfico de pessoas tem enorme repercussão econômica. Segundo dados da Organização para a Segurança e a Cooperação na Europa, o tráfico de seres humanos explora aproximadamente 2,5 milhões de pessoas, movimentando anualmente U\$ 32 bilhões, superando, em lucratividade, o tráfico de armas. Tráfico de pessoas movimenta US\$ 32 bilhões por ano

A lucratividade oriunda desta prática na maioria das vezes é rápida e prática. Há relatos de jovens que cobravam a quantia de $\mathrm{R} \$ 15,00$ (quinze reais) por cliente e eram obrigadas a repassarem o valor de $\mathrm{R} \$ 10,00$ (dez reais) aos patrões como sendo como forma de pagamentos sobre os custos que eles tinham com elas. Noutros casos, elas cobravam mais caro e repassavam a totalidade do valor aos traficantes. A prática do tráfico de pessoas possui baixo investimento e gera um lucro com altas cifras e de maneira rápida.

As vítimas que eram destinadas para o exterior, quando chegam, os traficantes desembolsam em torno de trinta mil dólares referentes a falsificação de documentos, transporte, estadia e alimentação entre outros. Estas, para conseguirem se libertar do tráfico, estas têm que quitar uma dívida de aproximadamente cinquenta mil dólares; com a estimativa desta ser paga em aproximadamente dois anos. Diante da incerteza, a cada dia a dívida aumenta e elas a continuam pagando (mesmo sendo impossível de arcar com o custo dela).

No mundo, a movimentação que o tráfico de pessoas gera em torno de sete a nove bilhões de dólares. Países como Bélgica, Itália, Alemanha e França, possuem uma movimentação de 4,5 milhões de dólares referentes a prostituição e pornografia.

Segundo a Pesquisa sobre Tráfico de Mulheres, Crianças e Adolescentes para Fins de Exploração Sexual Comercial no Brasil (PESTRAF 2003), os países que mais "enviam" pessoas ao lenocínio são: Gana, Nigéria e Marrocos, na África; Brasil e Colômbia, na América Latina; República Dominicana, no Caribe; Filipinas e Tailândia, no sudeste da Ásia. Os países que mais recebem as vítimas decorrente de tal são no continente europeu como Alemanha, Espanha, Holanda, Itália, Portugal, Suíça; na América países como Estados Unidos, Paraguai e atingindo o continente asiático como o Japão.

Normalmente, as rotas do tráfico são quase as mesmas da imigração. O movimento é sempre dos países subdesenvolvidos para os desenvolvidos onde o transporte aéreo é o meio mais 
comum de envio das vítimas. Existe o tráfico interno, este realizado dentro dos países, de região para região, onde nesses casos o transporte mais usado é o terrestre, sendo por meio de táxis, caminhões, ônibus e carros.

\section{SUJEITOS}

As mulheres correspondem a aproximadamente $83 \%$ das pessoas que são traficadas (54\% são mulheres, $44 \%$ são crianças, e apenas $2 \%$ são homens, mundialmente). É notável a percepção o porquê das mulheres para tal prática, estas sempre foram ícones de beleza, desde os tempos mais remotos. No Brasil, as propagandas publicitárias na sua grande maioria, sempre utilizam a figura feminina como imagem para a venda dos produtos, onde o artifício utilizado pelas empresas é a exposição destas seminuas ou até mesmo nuas.

Os países estrangeiros possuem uma imagem da mulher brasileira onde são belas, com corpos perfeitamente esculpidos e munidas de muita sensualidade. Quem nunca viu uma propaganda de cerveja com mulheres de biquíni ou trajes na qual grande parte do corpo fica a mostra? Proveniente disso e turistas vem ao Brasil para conhecer a beleza e atraídos por tal, vem para praticarem o turismo sexual, onde muitos deles lotam aviões (os chamados charters), destinados diretamente para pontos estratégicos, principalmente a região Nordeste onde estão situados os principais pontos de tráfico de pessoas e a exploração sexual.

As mulheres que acabam se prostituindo de forma voluntária tornam-se os alvos mais vulneráveis. Elas quase sempre são originárias de famílias em condições de pobreza extrema, são mulheres que fazem de seus corpos, em troca de um prolongamento de suas vidas e das de suas famílias; não possuem escolaridade, muitas sofreram algum tipo de violência doméstica, outras são obrigadas por seus pais a se prostituírem, na maioria das vezes tiveram gravidez precoce, ou sofreram algum outro tipo de trauma de cunho sexual na infância.

Existem também mulheres que possuem boa formação, que possuíam empregos anteriormente, e que infelizmente acabaram sendo agregadas para o tráfico. Grande parte dessas mulheres foi iludida por seus sonhos de irem trabalhar mundo afora, ou de se tornarem famosas modelos, ou ainda de conseguir um nível mais alto para um conforto maior da família. Muitas delas tornam-se viciadas em drogas, engravidam, contraem doenças sexualmente transmissíveis, sofrem ataques físicos e ameaças dos clientes e dos traficantes, e são diariamente estupradas por seus "donos". Em meio a tanto desespero, várias acabam cometendo suicídio.

As crianças também são vítimas latentes deste delito, estas são utilizadas para várias práticas, tanto de cunho sexual como para o trabalho forçado. Sua utilização para a força de trabalho, na qual, a grande maioria são arrancadas de suas famílias, ou vendidas, sendo em moeda de troca por comida e dinheiro, para trabalharem de forma quase que escrava. Estas preferidas pelos traficantes porque, em decorrência da pouca idade, não reclamam muito, são mais passíveis a receberem ordens e por fim são amedrontadas onde a violência psicológica lhes tornam reféns. Quando não servem mais para o trabalho ou a exploração sexual, são revendidos ou são retirados os seus órgãos para serem comercializados.

Além do aliciamento das crianças para trabalhos forçados, essas também utilizadas para a exploração sexual, onde são levadas para casas de prostituição onde são comercializadas junto com outras mulheres. Normalmente, as meninas são mais requisitadas para o tráfico sexual do que os meninos, tendo as virgens um grande valor de mercado, sendo leiloadas e podendo valer muito mais do que o próprio gasto que os traficantes tiveram. Além de terem que se prostituir, as crianças são fotografadas e filmadas fazendo sexo seja entre elas, seja com os traficantes. Suas fotos e vídeos vão parar na internet, onde outros milhares de pedófilos do mundo inteiro podem matar a sede de sua doença. 
O criminoso neste tipo de delito age, na grande maioria dos casos se passando como agenciador pertencente a alguma agência de modelos ou como representante de empresas com filiais no Brasil.

O agente que recruta modelos, este se valendo de boa aparência e de boa lábia na qual usam do poder de persuasão para iludirem suas vítimas, levadas por pelo sonho de virarem modelos famosas. São chamadas a fazerem testes e selecionadas para desfiles com sessões de fotografias, onde todo cenário é montado para que seja o mais realístico possível fazendo com os pais permitam o uso da imagem delas.

O representante da empresa com filial no Brasil utiliza a oportunidade principalmente do intercâmbio com oportunidade de trabalho, mostrando-lhes imagens de outros países, de como são bonitos e como elas podem se dar bem lá fora além de locais .

Esses são alguns dos artifícios utilizados para enganar, pois os traficantes Quando adentram nos outros países, tomam conhecimento de que seus documentos são falsos e são obrigadas a trabalhar como escravas sexuais em boates, barcos, casas de prostituição, etc. Os traficantes possuem álbuns das mulheres fotografadas para a livre escolha dos clientes.

O traficante poderá exercer várias funções na rede do tráfico de pessoas, dentre elas a função de recrutador, onde este é o encarregado de realizar os convites para as vítimas ou tentar convencê-las a consentir com o transporte, mediante fraude, utilizando como artifícios as promessas de trabalho, bolsas de estudo ou pacotes de viagens. Este trata-se de uma pessoa física, ou às vezes até jurídica que, busca persuadir o indivíduo a realizar a viagem.

$\mathrm{Na}$ função de transportador, o traficante é o responsável por realizar o transporte da vítima, acompanhando a vítima até o seu destino final, outras somente as acompanham até o embarque ou providenciam os trâmites como emissão de passagens, documentação necessária para o transporte, estadia entre outras.

O que age como explorador consiste naquele que explora a vítima de diversas formas, como por exemplo, para a exploração sexual, o trabalho forçado, o trabalho escravo, a remoção de órgãos, tecidos ou partes do corpo e a adoção ilegal.

Responsável pelo Alojamento é aquele ou aquela que mantém a vítima sob seu poder, em alojamento que fica sob sua responsabilidade de manutenção. Este também mantém a segurança do estabelecimento e, portanto, a vigilância sobre a vítima.

Gerente é o responsável pela administração dos negócios.

Financiador /Beneficiário Principal é, em regra, o(a) chefe da organização, que detém a maior parte dos lucros e/ou que financia a prática criminosa, fornecendo dinheiro para o pagamento de transporte, locomoção de vítima e traficantes, manutenção dos estabelecimentos etc.

Dados da Polícia Federal revelam que são as mulheres em maioria as aliciadoras, recrutadoras ou traficantes, que somam cerca de $55 \%$ (cinquenta e cinco por cento) dos indiciados. Já o Departamento Penitenciário revela um número maior de homens presos por atividades criminosas relacionadas ao tráfico de pessoas. No Ministério da Saúde, cerca de 65\% (sessenta e cinco por cento) dos casos de agressão a vítimas de tráfico de pessoas foram cometidos por homens.

Os aliciadores brasileiros vêm de todas as classes sociais, alguns pertencem às elites econômicas, são proprietários ou funcionários de boates, e muitos exercem funções públicas nas cidades de origem ou de destino do tráfico de mulheres, crianças e adolescentes.

Muitas das vezes, as vítimas são obrigadas a aliciar outras mulheres e acabam se juntando à organização criminosa para a preservação de suas vidas. 
Vale lembrar que há nessas pesquisas e diagnósticos uma certa fragilidade dos dados sobre tráfico de pessoas, pois há instituições que ainda não estão preparadas para registrar esse tipo de crime, contribuindo para a subnotificação

\section{LEGISLAÇÃO ACERCA DO TRÁFICO DE PESSOAS}

O Brasil no plano internacional referente a proteção acerca dos direitos humanos, ratificou os principais tratados, que, além de criarem obrigações para o Brasil perante a Comunidade Internacional, também criaram obrigações internas, gerando novos direitos, que passaram a contar com uma última instância internacional de decisão quando todos os recursos disponíveis no Brasil falharem na realização da justiça.

$\mathrm{O}$ artigo 50 em seu parágrafo segundo trata dos direitos e garantias nela expressos não excluem outros decorrentes do regime e princípios por ela adotados e dos tratados internacionais de que o Brasil seja parte.

O tráfico de pessoas traz uma violação dos direitos humanos de uma forma ampla, que são traficadas com a finalidade de serem exploradas sexualmente. Estas são frequentemente torturadas, sexualmente abusadas, estupradas. Costumam ter seus documentos e passaportes apreendidos e têm que pagar para obtê-los de volta, o que raramente conseguem vivendo presas, reduzidas à condição de escravas.

No âmbito internacional, a Organização das Nações Unidas (ONU), no Protocolo de Palermo define tráfico de pessoas como o "recrutamento, transporte, transferência, abrigo ou recebimento de pessoas, por meio de ameaça ou uso da força ou outras formas de coerção, de rapto, de fraude, de engano, do abuso de poder ou de uma posição de vulnerabilidade ou de dar ou receber pagamentos ou benefícios para obter o consentimento para uma pessoa ter controle sobre outra pessoa, para o propósito de exploração" (2003).

O mesmo Protocolo também define a exploração como sendo "no mínimo, a exploração da prostituição de outrem ou outras formas de exploração sexual, o trabalho ou serviços forçados, escravatura ou práticas similares à escravatura, a servidão ou a remoção de órgãos". (ONU, 2003)

De acordo com o protocolo supracitado (ONU, 2003), quando se tratar apenas do tráfico de crianças, basta apenas o recrutamento, o transporte, a transferência, o alojamento ou o acolhimento para a caracterização de tráfico, sem a necessidade de comprovar ameaça, uso de força, rapto, fraude, engano e as demais formas previstas no artigo 3o do Protocolo, ou seja, há uma presunção do uso de meios ilícitos que favorece as crianças. Nos termos do Protocolo, criança significa qualquer pessoa, menina ou menino, com idade inferior a dezoito anos.

A ONU ainda atribui a definição para o tráfico humano, esta contida no Protocolo Adicional à Convenção das Nações Unidas contra o Crime Organizado Transnacional relativo à Prevenção, Repressão e Punição do Tráfico de pessoas, em especial de Mulheres e Crianças (2000) ${ }^{1}$.

A legislação interna referente ao tema sofreu consideráveis modificações conforme o a temática foi sendo abordada. No âmbito do direito penal, na legislação especial foi editada a Lei no 13.344, de 06 de outubro de 2016, que dispõe sobre prevenção e repressão ao tráfico interno e internacional de pessoas e sobre medidas de atenção às vítimas. Lei esta alterou as Leis no 6.815, de 19 de agosto de 1980, o Decreto-Lei no 3.689, de 3 de outubro de 1941 (Código de Processo Penal), e o Decreto-Lei no 2.848, de 7 de dezembro de 1940 (Código Penal); e revoga dispositivos do Decreto-Lei no 2.848, de 7 de dezembro de 1940 (Código Penal).

A lei supra inseriu o artigo 149-A no Código Penal, que configura o tráfico de pessoas agenciar, aliciar, recrutar, transportar, transferir, comprar, alojar ou acolher pessoa, mediante grave ameaça, violência, coação, fraude ou abuso. Trata-se de tipo misto alternativo, crime de

\footnotetext{
1 O Decreto no 5.017, de 12 de março de 2004, promulga o Protocolo Adicional à Convenção das Nações Unidas contra o Crime Organizado Transnacional Relativo à Prevenção, Repressão e Punição do Tráfico de pessoas, em Especial Mulheres e Crianças
} 
ação múltipla que pode ser praticado mediante a prática de qualquer das condutas. Há atos que denotam permanência, tais como transportar e alojar, casos em que a consumação se prolonga no tempo. É um crime bicomum, não existindo condição especial do agente ou da vítima. (CASTRO, 2016)

Em relação ao tráfico de pessoas a lei supracitada com o surgimento desta houve a revogação dos artigos 231 e 231-A do Código Penal.

Estas diferenças, criadas pela legislação interna e mantidas inalteradas, não condizem com os acordos e tratados internacionais sobre os direitos humanos, direitos das mulheres, dos trabalhadores e especialmente sobre o tráfico de pessoas, já ratificados pelo Brasil, que impõem medidas eficientes de prevenção e combate ao crime.

\section{CONCLUSÃO}

O tráfico de pessoas vai além das fronteiras entre os países, possuindo uma abrangência na qual deve haver uma proteção para os sujeitos que são atingidos diretamente com o cometimento deste. Delito este sendo de caráter pluriofensivo, o lenocínio é injusto com a liberdade de locomoção, a dignidade humana, a honra pessoal, os bons costumes, a liberdade sexual e, acima de tudo, a liberdade propriamente dita. É um crime tão ofensivo às pessoas que até mesmo os próprios presos não perdoam estupradores.

Infelizmente, não é de se admirar que o homem tenha tanta coragem para impor a ideia do lenocínio às pessoas. A sua ganância vem desde a idade da pedra, com a mera guerra do fogo. Desde então aqueles mais ambiciosos lutam para obter o máximo de lucro e poder, seja a qualquer custo e por cima de quem for. Mas a verdade é que ninguém pode imaginar a dor que o lenocínio traz às vítimas, a não ser elas mesmas. O trauma causado nas vítimas deste delito é de forma traumatizante na qual estas precisam de acompanhamento médico e psiquiátrico o resto da vida.

\section{REFERÊNCIAS}

ALVES, José. Casa de Prostituição Infantil é Descoberta. Disponível em: $<w w w . s i s t e m a s . a i d s . g o v . b r>$. Acesso em 14/04/2010.

BONJOVANI, Mariane Strake. Tráfico Internacional de Seres Humanos. São Paulo: Damásio de Jesus, 2004.

BRASIL, Constituição da República Federativa do Brasil de 1988. Disponível em: <http://www.planalto.gov.br/ccivil_03/Constituicao/Constituicao.htm>. Acesso em: 12 jun. 2018.

Decreto-Lei no 2.848, de 7 de dezembro de 1940, Código Penal. Disponível em: <http://www.planalto.gov.br/ccivil_03/decreto-lei/Del2848compilado.htm>. Acesso em 12 jun. 2018.

Lei no 13.344, de 06 de outubro de 2016. Dispõe sobre prevenção e repressão ao tráfico interno e internacional de pessoas e sobre medidas de atenção às vítimas. Disponível em: < http://www.planalto.gov.br/ccivil_03/_ato2015-2018/2016/lei/L13344.htm>. Acesso em 12 jun. 2018.

Decreto no 5017, de 12 de março de 2004. Promulga o Protocolo Adicional à Convenção das Nações Unidas contra o Crime Organizado Transacional Relativo à Prevenção, Repressão e Punição do Tráfico de Pessoas, em Especial Mulheres e Crianças. 
<http://www.planalto.gov.br/ccivil_03/_Ato2004-2006/2004/Decreto/d5017.htm> Acesso em 02 jun 2018.

GONÇALVES, Victor Eduardo Rios. Direito penal esquematizado: parte especial. São Paulo: Saraiva, 2016.

MIRABETE, J. F; FABBRINI, R.N. Manual de Direito Penal. 27o ed. São Paulo: Atlas, 2010.

NUCCl, Guilherme de Souza. Crimes contra a dignidade sexual. 2a ed. São Paulo, Revista dos Tribunais, 2010.

Plano Nacional de Enfrentamento a o Tráfico de Pessoas. Secretaria Nacional de Justiça. Brasília: SNJ, 2008.

SHECARIA, Sergio Salomão; SILVEIRA, Renato de Mello Jorge. O Tráfico Internacional de Mulheres e Crianças. Disponível em: <http://www.direitopenal.adv.br>. Acesso em 29 mai. 2018 